Research Journal of Applied Sciences 5 (4): 303-308, 2010

ISSN: $1815-932 \mathrm{X}$

(C) Medwell Journals, 2010

\title{
Adaptive Based Controller for Three Phase UPQC as Solution for Power Quality Improvement in Sensitive Load
}

\author{
P. Jenopaul and T. Ruban Deva Prash \\ Noorul Islam University, Tamil Nadu, India
}

\begin{abstract}
This study proposes a new efficient control system for unified power quality conditioner it is possible to reduce the voltage fluctuations like sag and swell conditions and current and voltage harmonics isolation in distribution systems. The UPQC which can be used at the PCC for improving power quality is modeled and simulated using proposed control strategy and the performance is compared by applying it to a distribution system with and without UPQC. Performance of this UPQC has been evaluated with a typical industrial load with realistic parameters supplied by a polluted distribution network. Dynamic model of the UPQC is developed in the MATLAB/SIMULINK environment and the simulation results demonstrating the power quality improvement in the system are presented for different supply and load conditions.
\end{abstract}

Key words: Power quality, UPQC, point of common coupling, harmonics, reactive power, voltage sag, voltage swell, MATLAB/SIMULINK

\section{INTRODUCTION}

Because of the application of sophisticated and more advanced software and hardware for the control systems the power quality has become one of the most important issues for power electronic engineers. With great advancement in all areas of engineering particularly, in signal processing, control systems and power electronics, the load characteristics have changed completely. In addition to this, loads are becoming very sensitive to voltage supplied to them. The loads based on power electronic devices generally pollute the nearby network by drawing non sinusoidal currents from the source. The rapid switching of electronic devices creates additional Problems. This makes voltages and currents at Point of Common Coupling (PCC) highly distorted (Khadkikar et al., 2006). One of the best solution to compensate both current and voltage related problems, simultaneously, it is the use of Unified Power Quality Conditioner (UPQC) (Singhy and Venkateswarlu, 2010; Zhu et al., 2005). One of the electrical system adapter structure is back to back inverter. According to the controlling structure, back to back inverters might have different operations in compensation. For example, they can operate as shunt and series active filters to simultaneously compensate the load current, harmonics and voltage isolations. This is called UPQC. A UPQC can be installed to protect the sensitive load inside the plant as well as to restrict entry of any distortion from load side. This dual functionality makes the UPQC as one of the most suitable devices that could solve the problems of both consumers as well as of utility. UPQC thus can help to improve voltage profile and hence the overall health of power distribution system. The application of UPQC to compensate the swell, sag and unbalanced voltage, reactive power, current harmonics and voltage harmonics through shunt and series voltage source inverter.

Voltage source inverter has to generate sinusoidal voltage with the frequency, amplitude and the phase determinant by the control system. In order to clear the switching oscillation, a passive filter is applied at the output of each inverter. At the output of shunt inverter, high pass secondary order LC or first order RC filter is allocated and at the output of series inverter, low pass second order LC or resonance filter is allocated UPQC Controller provides the compensation voltage through the UPQC series inverter and provides conditioning current through the shunt inverter by instantaneous sampling of load current and source voltage and current.

Control strategy for UPQC: The control strategy is basically the way to generate reference signals for both shunt and series APFs of UPQC. The compensation effectiveness of the UPQC depends on its ability to follow with a minimum error and time delay to calculate the reference signals to compensate the distortions, unbalanced voltages or currents or any other undesirable condition.

\section{MATERIALS AND METHODS}

Selecting the controlling method: UPQC is vastly studied by several researches as an infinite method for power quality conditioner. Different UPQC controlling methods can be classified in three following classes: time-domain controlling method, frequency domain controlling method

Corresponding Author: P. Jenopaul, Noorul Islam University, Tamil Nadu, India 


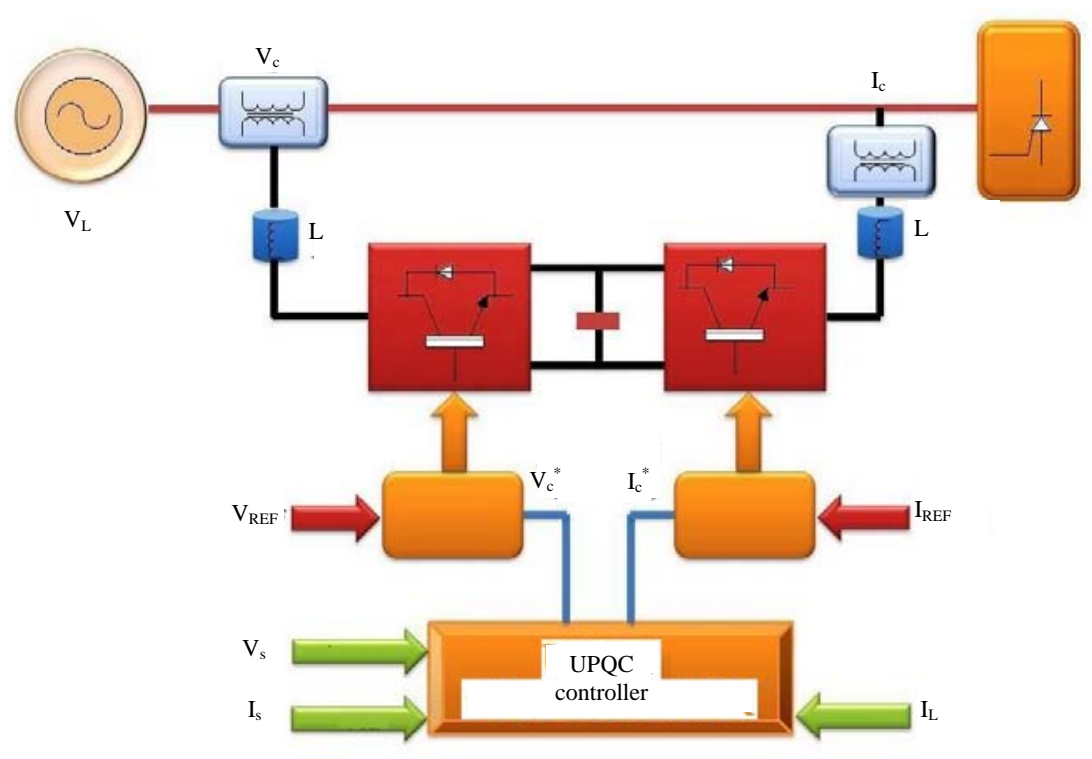

Fig. 1: Control system

and new techniques. Fourier method is one of the methods can be named as frequency-domain methods. The methods such as P-Q Theory (Zhili et al., 2006; Akagi and Hirokazu, 2007), ZVSinstantaneous reactive power (Elnady and Salama, 2001), algorithms based on the synchronous d-q reference frame, instantaneous power balance method (Mohamadrezapour et al., 2009), synchronous detection algorithm, direct detection algorithm and notch filter based controlling method are some can be mentioned for time domain methods. Dead beat control, space vector modulation and wavelet conversion are some of the new techniques (Elnady et al., 2002). Three general standards considered to select the controlling methods are load characteristics, required accuracy and application facility. All method end in to a similar results when the reference signal is calculated under balanced and sinusoidal conditions where each end in to a different results under unbalanced and non sinusoidal conditions. Dead beat controlling method presents the best operation among the others but more expense should be paid for its calculations.

Among the introduced methods the adaptive control method seems to be more appropriate. The fact is that it needs the sinusoidal and balanced voltage and it is not sensitive to voltage distortions and is relatively simple. In result, the response time of the control system shortens.

Controller design: The control system of proposed system is shown in Fig. 1. This comprises of three following parts:
- Reference signal generation (PLL)

- Shunt inverter control

- Series inverter control

Reference signal generation of the controller (PLL): The critical problem of a unified power quality conditioner is to find an algorithm which can obtain an accurate harmonic reference signal for control purpose. Conventional control algorithms, such as using the instantaneous reactive power theory (Fujita and Akagi, 1998) or instantaneous symmetrical components (Ghosh and Ledwich, 2002), the shunt and series $\mathrm{AF}$ currents/voltages are sensed and controlled to match their respective computed reference components there by increasing the number of sensors and computational delays (Mohamadrezapour et al., 2009). In this study, a detecting method based on adaptive noise canceling theory is used and is adopted to measure the harmonic components of the nonlinear load current and load voltage is implemented. Let the load current, input frequency and terminal voltage be the input to the PLL. Three phase distorted supply voltages are sensed and given to the PLL which generates sine terms.

The sensed supply voltage is multiplied with a suitable value of gain before being given as an input to the PLL. Here $\mathrm{K}=1 \ldots \mathrm{N}$ be the gain value assigned for controlling.

Here, $\mathrm{I}_{\mathrm{L}}$ is the load current $\mathrm{V}_{\mathrm{T}}$ is the load voltage, $\mathrm{Y}$ is the output signal of the adaptive detecting circuit, $\omega$ is the output signal of the adaptive detecting circuit and $\mathrm{F}$ is the fundamental reference frequency which is in phase with ac source voltage. From the theory of ANC and (Kazemi et al., 2006) as the input sinusoidal reference 


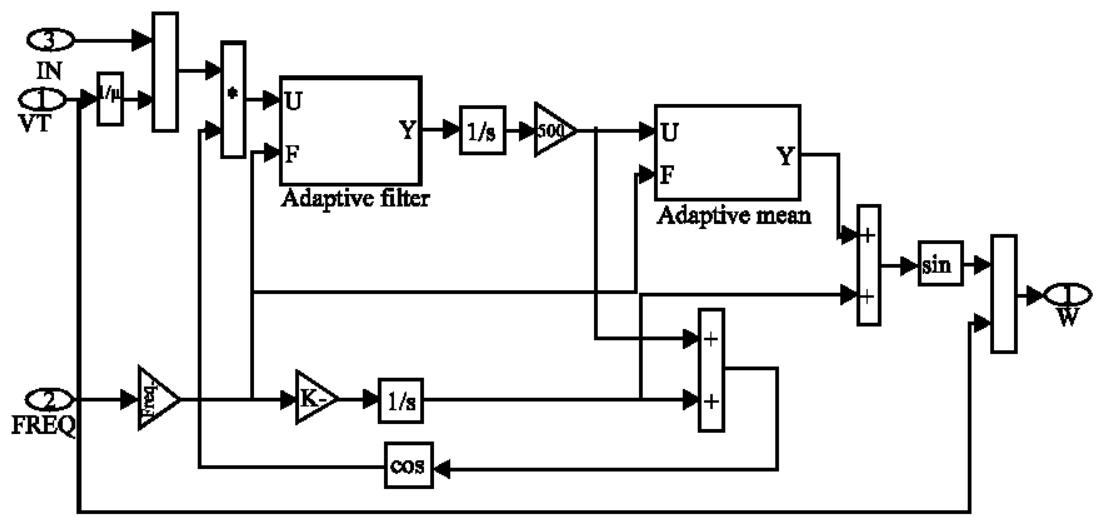

Fig. 2: Prposed reference signal generation (PLL)

signal, i.e., the Fundamental componenpt of the system voltage has the same frequency and in phase with the desired fundamental components of load current and load voltage, the dc component of the output of integrator will tune accordingly until they are equal in magnitude. The corresponding fundamental real components of the current and voltage are then extracted from the sampled load current and load voltage. Under the action of ANC loop in steady state the output current and voltage If and $\mathrm{V}_{\mathrm{S}}$ of detecting circuit have no larger include the fundamental real components, the dc component of the integrator output will keep a constant value which is in proportional to the magnitude of the fundamental real component of load:

$$
\begin{gathered}
\mathrm{I}_{\mathrm{f}}=\mathrm{I}_{\mathrm{L}}-\mathrm{kE}_{\mathrm{m}} \sin \omega \mathrm{t}\left(\mathrm{K}_{0}+1 / \omega R \mathrm{RC}_{0}^{\mathrm{t}} \mathrm{I} \mathrm{E}_{\mathrm{m}} \sin \omega \mathrm{t}\right. \\
=\mathrm{I}_{\mathrm{L}}-\mathrm{kK}_{0} \mathrm{E}_{\mathrm{m}} \sin \omega \mathrm{t}-\mathrm{kK}_{1} \mathrm{E}_{\mathrm{m}} \sin \omega \mathrm{t}
\end{gathered}
$$

Where:

$$
\mathrm{K}_{1}=1 / \omega \mathrm{RCI} \mathrm{f}_{\mathrm{f}} \cdot \mathrm{E}_{\mathrm{m}} \sin \omega \mathrm{td} \omega \mathrm{t}
$$

$$
\begin{gathered}
\mathrm{V}_{\mathrm{s}}=\mathrm{V}_{\mathrm{L}}-\mathrm{kE}_{\mathrm{m}} \sin \omega \mathrm{t}\left(\mathrm{K}_{0}+1 / \omega R \mathrm{RC}_{0}^{\mathrm{t}} \mathrm{V}_{\mathrm{s}} \mathrm{E}_{\mathrm{m}} \sin \omega \mathrm{td} \omega \mathrm{t}\right. \\
=\mathrm{V}_{\mathrm{s}}-\mathrm{kK}_{0} \mathrm{E}_{\mathrm{m}} \sin \omega \mathrm{t}-\mathrm{kK}_{1} \mathrm{E}_{\mathrm{m}} \sin \omega \mathrm{t}
\end{gathered}
$$

Where:

$$
\begin{gathered}
\mathrm{K}_{1}=1 / \omega R C \mathrm{I}_{\mathrm{f}} \cdot \mathrm{E}_{\mathrm{m}} \sin \omega \mathrm{td} \omega \mathrm{t} \\
\mathrm{I}_{\mathrm{L}}=\mathrm{I}_{\mathrm{P}}+\mathrm{I}_{\mathrm{Q}}+\mathrm{I}_{\mathrm{H}} \\
\mathrm{V}_{\mathrm{L}}=\mathrm{V}_{\mathrm{P}}+\mathrm{V}_{\mathrm{Q}}+\mathrm{V}_{\mathrm{H}}
\end{gathered}
$$

Where:

$\mathrm{I}_{\mathrm{p}}=$ Fundamental active component load current

$I_{q}=$ Fundamental reactive component of load current

$\mathrm{I}_{\mathrm{h}}=$ Harmonic components in load current

$\mathrm{V}_{\mathrm{p}}=$ Fundamental active component of load voltage

$\mathrm{V}_{\mathrm{q}}=$ Fundamental reactive component of load voltage

$\mathrm{V}_{\mathrm{h}}=$ Harmonic components in load voltage. Then:

$$
\begin{gathered}
I_{f}=I_{L}-k \cdot K_{0} \cdot E_{m} \sin \omega T \\
I_{f}=I_{P}+I_{Q}+I_{H}-k K_{0} \cdot E_{m} \sin \omega T
\end{gathered}
$$

$$
\begin{gathered}
\mathrm{I}_{\mathrm{F}}=\mathrm{I}_{\mathrm{Q}}+\mathrm{I}_{\mathrm{H}} \\
\mathrm{I}_{\mathrm{P}}=\mathrm{k} \cdot \mathrm{K}_{0} \cdot \mathrm{E}_{\mathrm{m}} \sin \omega \mathrm{T}
\end{gathered}
$$

The output signal of the adaptive detecting current and voltage are just the reactive power and harmonic components of the nonlinear load voltage and current.

Control scheme of shunt inverter control: Figure 2 shows the UPQC Shunt Inverter block diagram using adaptive controller implemented in simulink. Where the sensitive load currents are $\mathrm{I}_{\text {load }}$. The measured load currents are fed in to adaptive controller. The fundamental sinusoidal functions are obtained through the using PLL using adaptive filters. Let the load current and current active filter be the input to the shunt firing unit. The gate signal obtained from this unit is the input to the IGBT. Thus obtaining gate signal by means of hysteresis current controlling technique is performed. The gate signal is obtained by means of using hysteresis current controlling technique. To detect the current to be compensated, reference current has to obtain. PLL value is improved by means of RMS value. RMS of load active current can be obtained by:

$$
\operatorname{RMS}(F(t))=\sqrt{\left.1 / T \int_{t-T}^{\mathrm{T}} \mathrm{f}(\mathrm{t})\right)^{2}}
$$

The computed currents are then given to the hysteresis controller along with the sensed three-phase current. The output of the hysteresis controller is gate signals of the VSI of the shunt AF. The shunt APF can be designed to operate as a controlled current source whose output current would be automatically controlled.

Finally the reference current wave form get generate the reference current and rms value of the load current is multiply we get the actual undistracted current wave form with respect to load current (Fig. 3). The error signal will generate by subtract the rms value of the reference current wave form into actual load current wave form the mean value taken by the current signal of shunt active filter: 


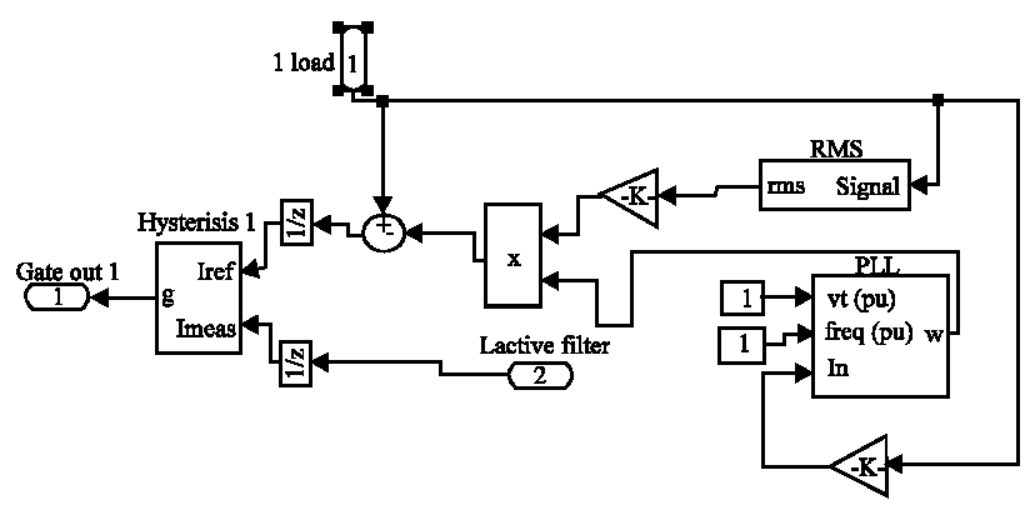

Fig. 3: Proposed shunt control strategy

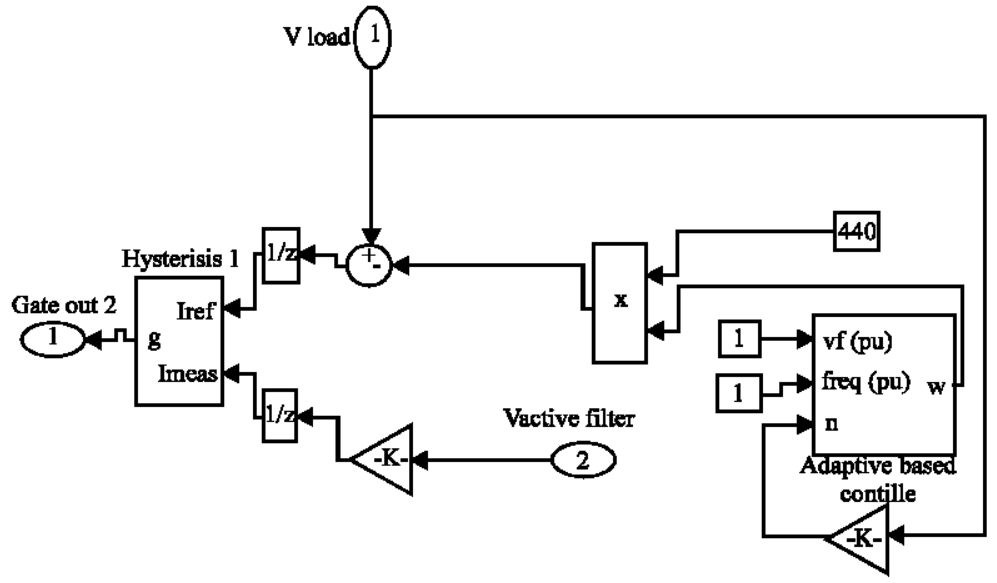

Fig. 4: Block diagram of proposed series control strategy

$$
\mathrm{I}_{\mathrm{ref}}=\mathrm{I}_{\text {load }}\left(\left(\mathrm{I}_{\text {load }}\right)\left(\mathrm{k} \cdot \mathrm{I}_{\mathrm{ms}}\right)\right)\left(\mathrm{I}_{\mathrm{pll}}\right)
$$

The two inputs are fed to the hysteresis band controller and the output fed to the IGBT control.

Control scheme of series inverter control: A simple control methodology is developed to control the series inverter control. The series filter is and the injected series filter voltage makes the desired voltage at the load terminals. The output of PLL is same for both shunt and series part. Let the load voltage and voltage active filter be the input to the series firing unit. The computed value of PLL is then multiplied with the desired peak value of the PCC phase voltage which becomes the three-phase reference PCC voltages, the desired peak value is $440 \mathrm{~V}$, thus it is shown in Fig. 4.

The computed voltages are then given to the hysteresis controller along with the sensed three-phase PCC voltages. The output of the hysteresis controller is gate signals of the VSI of the series AF. The hysteresis controller generates the gate signals such that the voltage at the PCC becomes the desired sinusoidal reference voltage. Therefore, the injected voltage across the series cancels out the harmonics present in the supply voltage. The complete system (converters, control circuitry, supply and load) has been simulated using SIMULINK toolbox from MATLAB 7.9.

Test system used: To verify the performance of the UPQC, a variable load is connected at Pcc5 controlled such that it injects voltages $\left(\mathrm{v}_{\mathrm{cq}}, \mathrm{V}_{\mathrm{cb}}, \mathrm{V}_{\mathrm{cc}}\right)$ which cancel out the distortions and/or unbalance present in the supply voltages, thus making the voltages at the $\mathrm{PCC}\left(\mathrm{v}_{\mathrm{La}} ; \mathrm{v}_{\mathrm{L}}\right.$; $\mathrm{V}_{\mathrm{Lc}}$ ) perfectly balanced and sinusoidal with the desired amplitude. In other words, the sum of the supply voltage.

\section{RESULTS AND DISCUSSION}

The UPQC and its control system have been tested at different load/supply imperfections. Figure 5 shows series filter output voltage in the case of $20 \%$ voltage sag. Substation voltage is also changed during the simulation. 


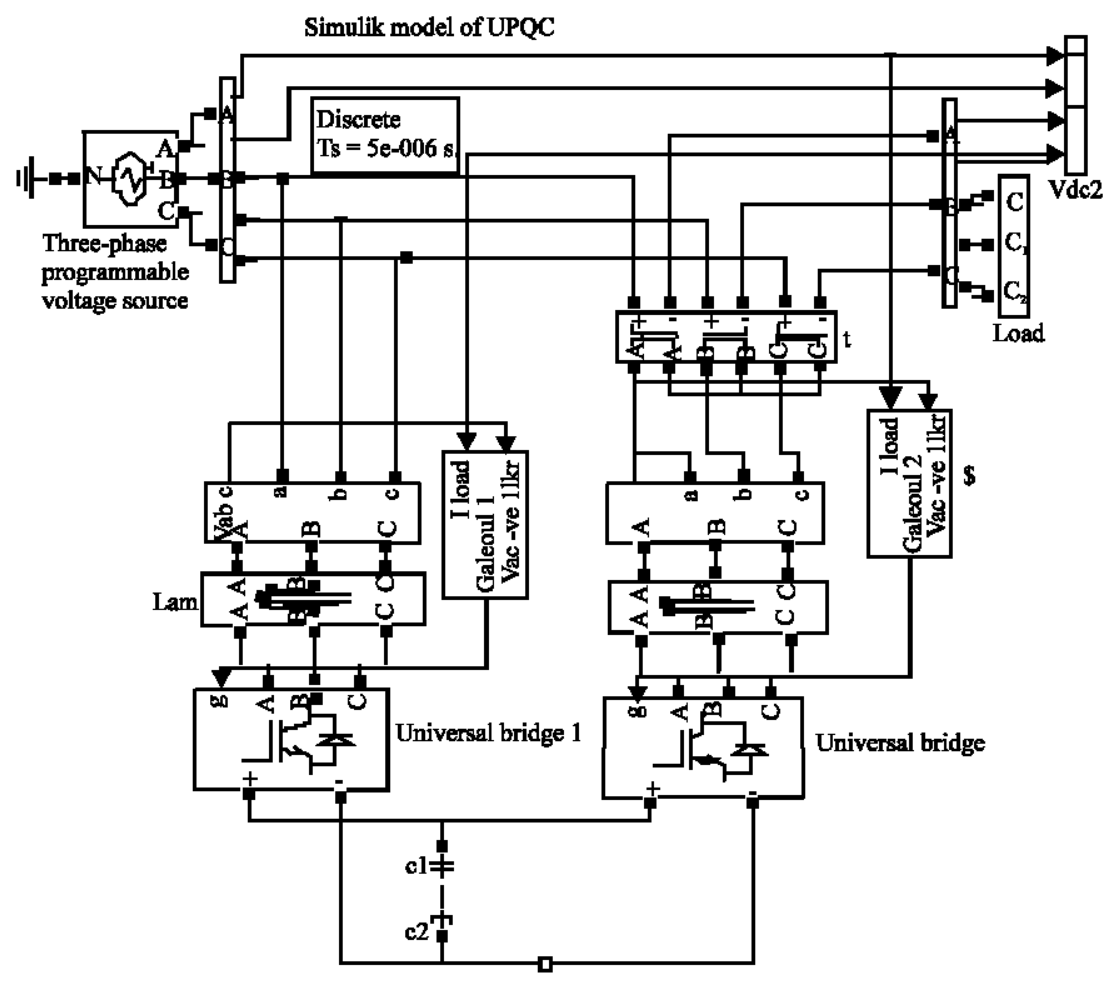

Fig. 5 : Complete model implemented in MATLAB SIMULINK
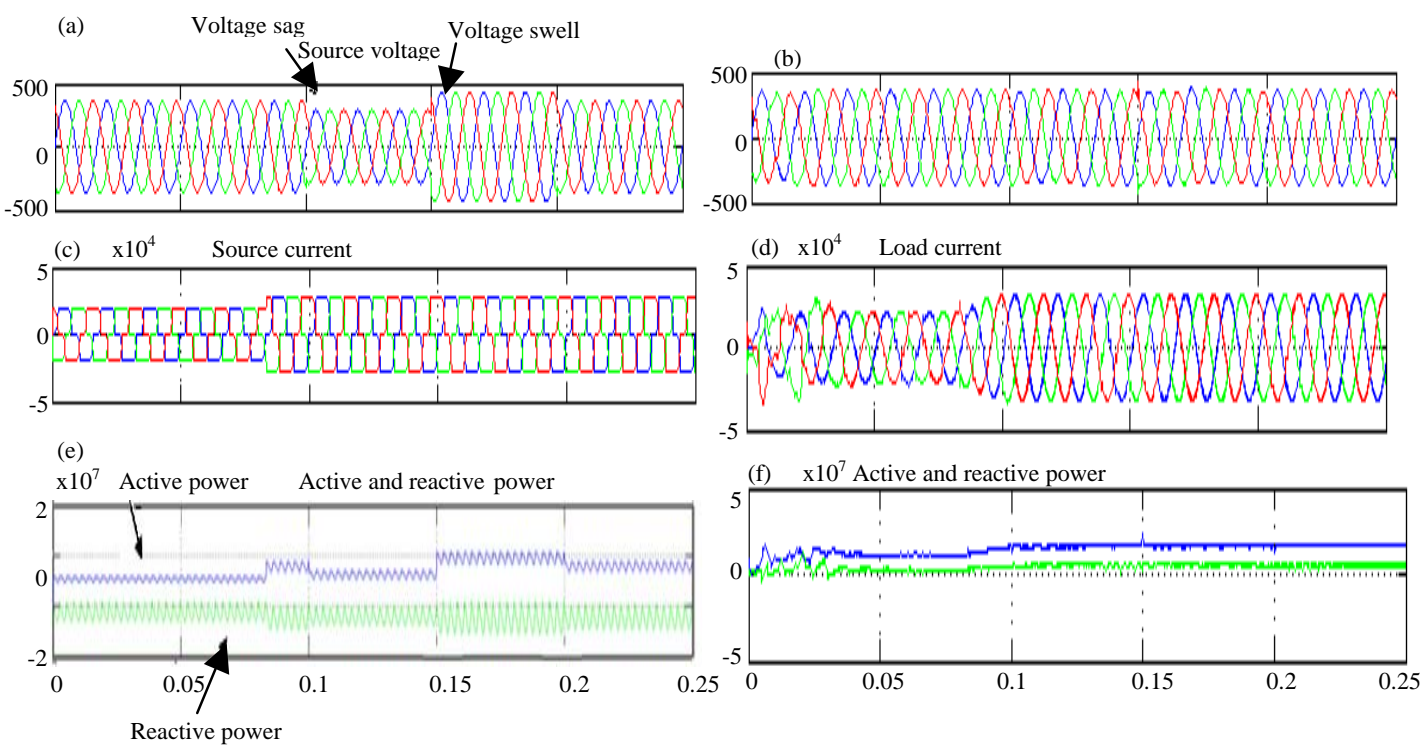

Fig. 6: (a) Source voltages under voltage sag and swell condition, (b) compensated voltage free from sagged and swell voltage, (c) distorted load current, (d) load current with compensation, (e) reactive power without compensation and (f) reactive power with compensation

Figure $6(\mathrm{a}-\mathrm{d})$ shows the source side voltage, load side voltage, source current and load current are simulated. Figure $6 \mathrm{a}$ shows the voltage distortions imposed to load from the grid are properly compensated by series inverter. In this simulation, the voltage sag occurred during the period of 0.1-0.15 sec as shown in Fig. 6. Voltage sag with $100 \mathrm{~V}$ amplitude occurs in source voltage. Figure $6 \mathrm{~b}$ shows the Compensated Voltage free from sagged and swell voltage. Figure $6 \mathrm{c}$ shows the load current polluted by sensitive load. The 
Total Harmonic Distortion (THD) is 3.2\% which is much lower than the limit value established by IEEE 519 Standard ( $8 \%$ for the system under consideration). Although the supply current THD is within the limits prescribed by the above mentioned standard, the load side voltage contains unacceptable ripple. The load voltages become unacceptably distorted after the UPQC is introduced into operation at $0.01 \mathrm{sec}$ as shown in Fig. 6d. In this particular case the load voltage THD is $1.2 \%$ whereas according to above mentioned standard it should not exceed $5 \%$ for $11 \mathrm{kV}$ and below. Figure 6e shows the reactive power lag at Pcc. Figure $6 f$ shows the reactive power maintain constant.

\section{CONCLUSION}

The simulation results shows that when unbalance and nonlinear occur in load current or unbalance and sag in source voltage, the above control algorithms eliminate the impact of distortion and unbalance of load current on the power line making the power fact of it unity. Meanwhile, the series compensator isolate the source voltage harmonics, shunt compensator provide threephase balanced and isolate the current harmonics for Loads. A MATLAB/SIMULINK based simulations is carried out in order to verify its performance.

\section{REFERENCES}

Akagi, H. and E. Hirokazu, 2007. Instantaneous Power Theory and Applications to Power Conditioning. John Wiley-IEEE Press, New York.

Elnady, A. and M.M.A. Salama, 2001. New functionalities of an adaptive unified power quality conditioner. Proc. IEEE-PES Winter Meet., 1: 295-300.

Elnady, A., A. Goauda and M.M.A. Salama, 2002. Unified power quality with a novel control algorithm based on wavelet tansform. Proc. Can. Conf. Electr. Comp. Eng., 2: 1041-1045.
Fujita, H. and H. Akagi, 1998. The unified power quality conditioner: The integration of series active filters and shunt active filters. IEEE Trans. Power Electron., 13: $315-322$.

Ghosh, A. and G. Ledwich, 2002. Power Quality Enhancement Using Custom Power Devices. Kluwer Academic Publishers, Boston, USA., pp: 1-54.

Kazemi, A., M. Sarlak and M. Barkhordary, 2006. An adaptive noise canceling method for singlephase unified power quality conditioner. Proceedings of the 1st IEEE Conference on Industrial Electronics and Applications, May 24-26, Singapore, pp: 1-6.

Khadkikar, V., A. Chandra, O. Berry and T.D. Nguyen, 2006. Conceptual study of unified power quality conditioner (UPQC). Proceeding of the IEEE International Symposium on Industrial Electronics, July 9-13, Montreal, Que., pp: 1088-1093.

Mohamadrezapour, Y., M.B. Bana Sharifian, M.R. Feyzi and S.H. Hosseini, 2009. Design and simulation of UPQC by synchronous reference frame theory considering loading of series and shunt inverters. J. Applied Sci., 9: 2599-2605.

Singhy, B. and P. Venkateswarlu, 2010. A simplified control algorithm for three-phase, four-wire unified power quality conditioner. J. Power Electron., 10: $91-96$.

Zhili, T., L. Xun, C. Jian, K. Yong and D. Shanxu, 2006. A direct control strategy for UPQC in three-phase four-wire system. Proceedings of the CES/IEEE 5th International Power Electronics and Motion Control Conference, Aug. 14-16, Shanghai, pp: 1-5.

Zhu, P.C., X. Li, Y. Kang and J. Chen, 2005. Analysis and experimental verification of a control scheme for unified power quality conditioner. Int. J. Energy Technol. Policy, 3: 253-268. 